\title{
Water-soluble complex formation of fullerenes with a biocompatible polymer
}

\author{
Tetsuya Ohata ${ }^{1}$, Kazuhiko Ishihara ${ }^{2}$, Yasuhiko Iwasaki ${ }^{3}$, Arunee Sangsuwan ${ }^{3}$, Shota Fujii ${ }^{4,5}$, Kazuo Sakurai ${ }^{4,5}$, \\ Yuki Ohara $^{1}$ and Shin-ichi Yusa ${ }^{1}$ \\ Fullerenes $\left(\mathrm{C}_{60}\right.$ or $\left.\mathrm{C}_{70}\right)$ and water-soluble poly(2-(methacryloyloxy)ethyl phosphorylcholine) (PMPC$)$ were mixed by physical \\ means to prepare water-soluble fullerene/PMPC $n$ complexes. The ultraviolet-visible absorption spectra confirmed the presence of \\ aqueous solutions with high fullerene concentrations. The fullerene/PMPC ${ }_{n}$ complexes were characterized using light scattering \\ measurements, small-angle X-ray scattering measurements and transmission electron microscopic observations. The complexes \\ generated singlet oxygen upon visible light irradiation.
}

Polymer Journal (2016) 48, 999-1005; doi:10.1038/pj.2016.60; published online 8 June 2016

\section{INTRODUCTION}

Fullerenes have been investigated for applications such as novel pharmaceuticals and cosmetics. ${ }^{1} \mathrm{C}_{60}$ fullerenes and their derivatives have been reported to possess activity as enzyme inhibitors, ${ }^{2}$ antivirals, ${ }^{3}$ DNA scission agents, ${ }^{4}$ radical quenchers ${ }^{5}$ and photodynamic therapy (PDT) agents. ${ }^{6}$ In addition, $\mathrm{C}_{60}$ and $\mathrm{C}_{70}$ fullerenes have been proposed as photosensitizers for PDT to eliminate cancerous tissue because fullerenes can efficiently generate active oxygen upon visible light irradiation. ${ }^{7}$ However, biological applications of fullerenes have been limited because the solubility of fullerenes in water is extremely low. ${ }^{8}$ Various $\mathrm{C}_{60}$ fullerene derivatives have been synthesized to improve water solubility, ${ }^{9}$ and methods to improve the solubilization of fullerenes in water have been studied. ${ }^{10,11}$ In addition, solubilization of $\mathrm{C}_{60}$ in water has been investigated using inclusion complexes composed of $\mathrm{C}_{60}$ and host molecules, such as cyclodextrin and calixarene, ${ }^{12-15}$ micelles, ${ }^{16}$ liposomes ${ }^{17}$ and poly(N-vinylpyrrolidone) (PVP). ${ }^{18,19}$ In particular, PVP can form water-soluble complexes with fullerenes simply by grinding them together in a mortar, which results in charge transfer interactions. Complexation with PVP can better solubilize fullerenes at high concentrations compared with other methods.

Successful PDT requires the accumulation of the photosensitizer only around cancerous tissue. Vascular endothelium in cancerous tissue contains pores on the order of tens to hundreds of nanometers $(\mathrm{nm})$, which are not observed in healthy tissue. If the size of a drug is less than several nanometers, then the drug is removed quickly through kidney clearance. If the size of a drug is $>400 \mathrm{~nm}$, then it is removed quickly by macrophages. However, a drug with a size on the order of tens to a hundred nanometers can accumulate in cancerous tissue through an enhanced permeation and retention effect. ${ }^{20}$ Drugs within this size range can remain in cancerous tissue for a long period because the lymphatic vessels around cancerous tissue are undeveloped with an incomplete collection mechanism. Thus PDT photosensitizers accumulated around cancerous tissue can damage and kill only cancer cells by the active oxygen generated upon light irradiation.

The vinyl monomer, 2-methacryloyloxyethyl phosphorylcholine (MPC), has a pendant phosphorylcholine group, which is ubiquitous on the surface of cell membranes. The phosphorylcholine group has a betaine structure and a hydrophilic nature. ${ }^{21,22}$ The MPC homopolymer (Figure 1a) $\mathrm{PMPC}_{n}$ is well studied as a biomaterial because it shows inhibition of both blood coagulation and immunoresponses. ${ }^{23}$

In this study, $\mathrm{PMPC}_{n}$, with a well-controlled structure, was prepared via reversible addition-fragmentation chain transfer (RAFT) radical polymerization. Fullerene and $\mathrm{PMPC}_{n}$ powders were mixed using an agate mortar to form water-soluble fullerene/PMPC ${ }_{n}$ complexes. The complexation of fullerenes with $\mathrm{PMPC}_{n}$ can solubilize fullerenes in water (Figure 1b). The generation of singlet oxygen from the complexes upon visible light irradiation was confirmed by photooxidation of 9,10-anthracendipropionic acid (ADPA). Use of the complex in PDT was attempted because the water-soluble complexes are biocompatible owing to the surface $\mathrm{PMPC}_{n}$ chains (Figure 1c).

\section{EXPERIMENTAL PROCEDURE}

\section{Materials}

MPC was purchased from NOF Corp. (Tokyo, Japan), which was produced using a previously reported method. ${ }^{21} 4,4^{\prime}$-Azobis(4-cyanovaleric acid) (V-501, $98 \%)$ and poly (acrylic acid) (PAA, molecular weight $\left.\left(M_{\mathrm{w}}\right)=2.50 \times 10^{4}\right)$ from Wako Pure Chemical (Osaka, Japan) were used as received. 4-Cyanopentanoic

\footnotetext{
${ }^{1}$ Department of Applied Chemistry, Graduate School of Engineering, University of Hyogo, Hyogo, Japan; ${ }^{2}$ Department of Materials Engineering, School of Engineering, The University of Tokyo, Tokyo, Japan; ${ }^{3}$ Faculty of Chemistry, Materials and Bioengineering, Kansai University, Osaka, Japan; ${ }^{4}$ Department of Chemistry and Biochemistry, University of Kitakyushu, Fukuoka, Japan and ${ }^{5}$ CREST, Japan Science and Technology Agency, Saitama, Japan

Correspondence: Dr S Yusa, Department of Applied Chemistry, Graduate School of Engineering, University of Hyogo, 2167 Shosha, Himeji, Hyogo 671-2280, Japan.

E-mail: yusa@eng.u-hyogo.ac.jp

Received 3 February 2016; revised 25 April 2016; accepted 26 April 2016; published online 8 June 2016
} 
a

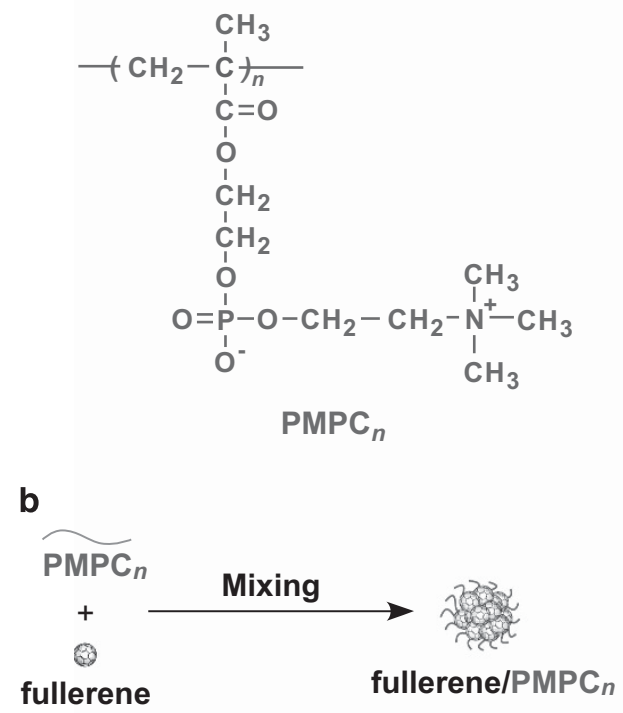

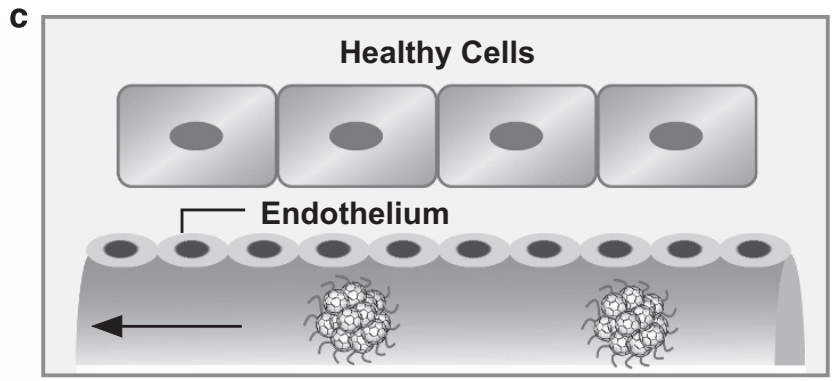

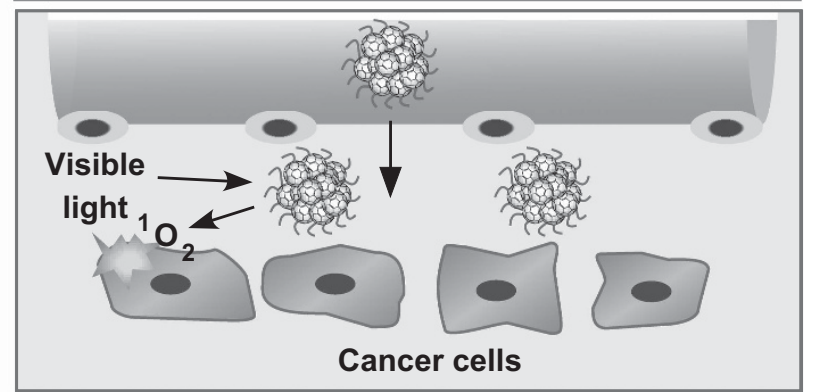

Figure 1 (a) Chemical structure of $\mathrm{PMPC}_{n}$. (b) Conceptual illustration of the preparation of the fullerene/PMPC $\mathrm{Complex}$. (c) Application of the fullerene/ $\mathrm{PMPC}_{n}$ complex for PDT. PMPC, poly(2-(methacryloyloxy)ethyl phosphorylcholine); PDT, photodynamic therapy. A full color version of this figure is available at the Polymer Journal online.

acid dithiobenzoate (CPD) was synthesized according to previously reported methods. ${ }^{24}$ Methanol was dried over $4-\AA$ molecular sieves and purified by distillation. The fullerenes $\left(\mathrm{C}_{60}: 98 \%\right.$ and $\left.\mathrm{C}_{70}: \geqslant 99 \%\right)$ from Sigma-Aldrich (St Louis, MO, USA) were used as received without further purification. Poly (methacrylic acid) (PMA) was prepared by neutralization of poly(sodium methacrylate) $\left(M_{\mathrm{w}}=9.50 \times 10^{3}\right)$ from Sigma-Aldrich (St Louis, MO, USA). ADPA was prepared according to a method previously reported. ${ }^{25}$ Water was purified using a Millipore (Billerica, MA, USA) Milli-Q system.

\section{Preparation of polyMPC $\left(\mathrm{PMPC}_{n}\right)$}

The MPC homopolymer was synthesized according to a modified version of previously reported methods. ${ }^{23}$ MPC (10.8 g, $\left.36.7 \mathrm{mmol}\right)$, CPD $(94.7 \mathrm{mg}$, $0.339 \mathrm{mmol})$ and V-501 $(47.6 \mathrm{mg}, 0.170 \mathrm{mmol})$ were dissolved in a mixed solvent $(36.7 \mathrm{ml})$ of water and methanol $(4 / 1 \mathrm{v} / \mathrm{v})$. The solution was degassed by purging with $\mathrm{Ar}$ gas for $30 \mathrm{~min}$. Polymerization was performed at $70^{\circ} \mathrm{C}$ for $6 \mathrm{~h}$. After the reaction, ${ }^{1} \mathrm{H}$ nuclear magnetic resonance (NMR) data indicated that the conversion was $100 \%$. The polymerization mixture was dialyzed against pure water for 2 days. ${ }^{26} \mathrm{PMPC}_{113}$ was recovered by a freeze-drying technique $(9.30 \mathrm{~g}, 85.0 \%)$. The number-average degree of polymerization (DP) and the number-average molecular weight estimated from NMR $\left(M_{\mathrm{n}}(\mathrm{NMR})\right)$ for $\mathrm{PMPC}_{113}$ were 113 and $3.36 \times 10^{4}$, respectively. The number-average molecular weight $\left(M_{\mathrm{n}}(\mathrm{GPC})\right)$ and molecular weight distribution $\left(M_{\mathrm{w}} / M_{\mathrm{n}}\right)$ estimated from gel-permeation chromatography (GPC) were $1.93 \times 10^{4}$ and 1.17, respectively. Low-molecular-weight $\mathrm{PMPC}_{64}\left(\mathrm{DP}=64, M_{\mathrm{n}}(\mathrm{NMR})=1.89 \times 10^{4}, M_{\mathrm{w}} / M_{\mathrm{n}}=1.23\right)$ and high-molecular-weight $\mathrm{PMPC}_{362} \quad\left(\mathrm{DP}=362, \quad M_{\mathrm{n}}(\mathrm{NMR})=1.07 \times 10^{5}\right.$, $\left.M_{\mathrm{w}} / M_{\mathrm{n}}=1.97\right)$ were prepared using methods similar to those described above.

\section{Preparation of fullerene/PMPC ${ }_{n}$ complexes}

A typical preparation of a fullerene/PMPC 113 complex is as follows: $\mathrm{PMPC}_{113}$ $\left(10 \mathrm{mg}, 2.98 \times 10^{-4} \mathrm{mmol}, M_{\mathrm{n}}(\mathrm{NMR})=3.36 \times 10^{4}, M_{\mathrm{w}} / M_{\mathrm{n}}=1.17\right)$ and $\mathrm{C}_{60}$ $\left(11 \mathrm{mg}, 15.3 \times 10^{-3} \mathrm{mmol}\right)$ powders were mixed in an agate mortar and then vigorously mulled for $30 \mathrm{~min}$. Water $(10 \mathrm{ml})$ was added to the powder mixture. The final polymer concentration $\left(C_{\mathrm{p}}\right)$ was adjusted to $1.0 \mathrm{gl}^{-1}$ by adding water. Insoluble material was removed by centrifugation at 6000 r.p.m. for $1 \mathrm{~h}$. All sample solutions were filtered with a $0.45-\mu \mathrm{m}$ membrane filter. Other concentrations of aqueous $\mathrm{C}_{60}$ and $\mathrm{C}_{70}$ solutions were prepared using methods similar to those described above.

\section{Measurements}

${ }^{1} \mathrm{H}$ NMR spectra were obtained with a Bruker BioSpin (Billerica, MA, USA) DRX-500 NMR spectrometer operating at $500 \mathrm{MHz}$. The sample solutions for ${ }^{1} \mathrm{H}$ NMR measurements were prepared using $\mathrm{D}_{2} \mathrm{O}$. The GPC measurements were performed using a refractive index detector equipped with a Shodex (Tokyo, Japan) 7.0- $\mu \mathrm{m}$ bead size GF-7 M HQ column (exclusion limit $\sim 10^{7}$ ) operated at $40{ }^{\circ} \mathrm{C}$ under a flow rate of $0.6 \mathrm{ml} \mathrm{min}^{-1}$. A phosphate buffer (pH 9) containing $10 \mathrm{vol} \%$ acetonitrile was used as the eluent. The $M_{\mathrm{n}}(\mathrm{GPC})$ and $M_{\mathrm{w}} / M_{\mathrm{n}}$ values were calibrated using standard sodium poly(styrene sulfonate) samples. Ultraviolet-visible (UV-vis) absorption spectra were recorded on a Jasco (Tokyo, Japan) V-630 UV-vis BIO spectrophotometer with a $1.0-\mathrm{cm}$ path length quartz cell. Dynamic light scattering (DLS) measurements were performed using a Malvern (Worcestershire, UK) Zetasizer nano $\mathrm{ZS}$ at $25^{\circ} \mathrm{C}$. A He-Ne laser $(4.0 \mathrm{~mW}$ at $632.8 \mathrm{~nm})$ was used as the light source. Sample solutions were filtered using a $0.45-\mu \mathrm{m}$ pore size membrane filter. The data were analyzed by the Malvern Zetasizer 6.20 software. Static light scattering (SLS) measurements were performed using an Otsuka Electronics Photal (Osaka, Japan) DLS-7000HL light scattering spectrometer. A He-Ne laser $(10.0 \mathrm{~mW}$ at $632.8 \mathrm{~nm})$ was used as the light source. Sample solutions for light scattering measurements were filtered with a $0.45-\mu \mathrm{m}$ pore size membrane filter. The weight-average molecular weight $\left(M_{\mathrm{w}}\right)$, the $z$-average radius of gyration $\left(R_{\mathrm{g}}\right)$, and the second virial coefficient $\left(A_{2}\right)$ values were estimated from the following relationship:

$$
\frac{K C_{\mathrm{p}}}{R_{\theta}}=\frac{1}{M_{\mathrm{w}}}\left(1+\frac{1}{3} R_{\mathrm{g}}{ }^{2} q^{2}\right)+2 A_{2} C_{\mathrm{p}}
$$

where $R_{\theta}$ is the difference between the Rayleigh ratio of the solution and that of the solvent, $K=4 \pi^{2} n^{2}\left(\mathrm{~d} n / \mathrm{d} C_{\mathrm{p}}\right) 2 / N_{\mathrm{A}} \lambda^{4}$, where $\mathrm{d} n / \mathrm{d} C_{\mathrm{p}}$ is the refractive index increment against $C_{\mathrm{p}}, N_{\mathrm{A}}$ is Avogadro's number and $q$ is the magnitude of the scattering vector. The $q$ value was calculated from $q=(4 \pi n / \lambda) \sin (\theta / 2)$, where $n$ is the refractive index of the solvent, $\lambda$ is the wavelength of light source ( $=632.8 \mathrm{~nm}$ ) and $\theta$ is the scattering angle. By measuring $R_{\theta}$ for a set of $C_{\mathrm{p}}$ and $\theta$, the values of $M_{\mathrm{w}}, R_{\mathrm{g}}$ and $A_{2}$ were estimated from Zimm plots. The known Rayleigh ratio of toluene was used to calibrate the instrument. The values of $\mathrm{d} n / \mathrm{d} C_{\mathrm{p}}$ at $633 \mathrm{~nm}$ were determined using an Otsuka Electronics Photal DRM-3000 differential refractometer. The $\mathrm{d} n / \mathrm{d} C_{\mathrm{p}}$ values for $\mathrm{C}_{60} / \mathrm{PMPC}_{113}$ and $\mathrm{C}_{70} / \mathrm{PMPC}_{113}$ were 0.722 and $0.833 \mathrm{ml} \mathrm{g}^{-1}$, respectively. Small-angle $\mathrm{X}$-ray scattering (SAXS) measurements were performed on a BL40B2 beamline at SPring-8, Hyogo, Japan. A $30 \times 30 \mathrm{~cm}^{2}$ imaging plate (Rigaku R-AXIS VII, Tokyo, Japan) detector was used and was placed 4.0 and $2.0 \mathrm{~m}$ away from the 
sample. The wavelength of the incident beam $(\lambda)$ was $0.10 \mathrm{~nm}$. This setup provided a $q$ range of $0.04-3.5 \mathrm{~nm}^{-1}$, where $q$ is the magnitude of the scattering vector defined by $q=(4 \pi n / \lambda) \sin \theta$ with a scattering angle of $2 \theta$. For the SAXS measurements, we used a vacuum sample chamber to remove the effects of the background from the window material and air. The X-ray transmittance of the samples was measured with an ion chamber located in front of the sample and a Si photodiode (Hamamatsu Photonics S8193, Shizuoka, Japan) placed after the sample. Detailed experimental procedures are reported elsewhere. ${ }^{27,28}$ Transmission electron microscopy (TEM) was performed using a JEOL (Tokyo, Japan) JEM-2100 at an accelerating voltage of $200 \mathrm{kV}$. Samples for TEM observations were prepared by placing one drop of an aqueous solution of the fullerene/PMPC 113 complex on a copper grid coated with support films. The samples were stained with phosphotungstic acid.

\section{Generation of singlet oxygen}

Photoirradiation was performed using an Asahi Spectra (Tokyo, Japan) Max-301 with light from a 300-W Xe lamp passing through a 420-nm cutoff filter. The light intensity was $6.5 \mathrm{~mW} \mathrm{~cm} \mathrm{~cm}^{-2}$ at $420 \mathrm{~nm}$. A quartz cuvette with a $1-\mathrm{cm}$ pass length was used. ADPA bleaching experiments were performed to confirm that singlet oxygen was generated by fullerene/PMPC 113 complexes in water, where ADPA was generated as a singlet oxygen acceptor. Aqueous solutions of ADPA and fullerene/PMPC 113 complexes were mixed, and the combined solution was irradiated at $\geqslant 420 \mathrm{~nm}$. The reaction was monitored by recording a decrease in the intensity of the absorption peak at $400 \mathrm{~nm}$ owing to ADPA as a function of the irradiation time.

\section{RESULTS AND DISCUSSION}

\section{Characterization of PMPC}

MPC was polymerized via a RAFT-controlled radical polymerization method using CPD; the MPC conversion was $100 \%$. The DP and $M_{n}$ (NMR) values estimated from NMR for $\mathrm{PMPC}_{113}$ were 113 and $3.36 \times 10^{4}$, respectively (Table 1$)$. The $M_{\mathrm{n}}(\mathrm{GPC})$ and $M_{\mathrm{w}} / M_{\mathrm{n}}$ values estimated from GPC were $1.93 \times 10^{4}$ and 1.17 , respectively. Low-molecular-weight $\left(M_{\mathrm{n}}(\mathrm{NMR})=1.89 \times 10^{4}\right)$ and high-molecularweight $\mathrm{PMPC}_{n}\left(M_{\mathrm{n}}(\mathrm{NMR})=1.07 \times 10^{5}\right)$ were also prepared. After polymerization, the percentage of conversion $(x)$ was monitored using ${ }^{1} \mathrm{H}$ NMR before purification, which can be estimated by comparing the integral intensity ratios between vinyl protons and pendant methylene protons. The value of $M_{\mathrm{n}}$ (theoretical) was calculated using the following equation:

$$
M_{\mathrm{n}}(\text { theory })=\frac{[\mathrm{MPC}]_{0}}{[\mathrm{CPD}]_{0}} \times \frac{x}{100} \times \mathrm{MW}_{\mathrm{MPC}}+\mathrm{MW}_{\mathrm{CPD}}
$$

where $[\mathrm{MPC}]_{0}$ is the initial molar concentration of MPC, $[\mathrm{CPD}]_{0}$ is the initial molar concentration of $\mathrm{CPD}, \mathrm{MW}_{\mathrm{MPC}}$ is the molecular weight of MPC and $\mathrm{MW}_{\mathrm{CPD}}$ is the molecular weight of CPD.

Proton NMR spectra for $\mathrm{PMPC}_{113}$ in $\mathrm{D}_{2} \mathrm{O}$ were obtained (Supplementary Figure S1). Signals in the 7.45-7.95 p.p.m. region were attributed to the dithiobenzoate group. The DP of $\mathrm{PMPC}_{113}$ was calculated as 113 from the area intensity ratio of peaks attributed to pendant methylene protons at 3.65 p.p.m. and terminal phenyl

Table 1 Molecular characteristics of $\mathrm{PMPC}_{n}$

\begin{tabular}{lcrccc}
\hline Polymer & $\mathrm{M}_{n}$ (theory) $\times 10^{-4}$ & $D P$ & $\mathrm{M}_{n}(N M R) \times 10^{-4}$ & $\mathrm{M}_{n}(G P C) \times 10^{-4}$ & $\mathrm{M}_{w} \mathrm{M}_{n}$ \\
\hline PMPC $_{64}$ & 1.89 & 64 & 1.89 & 0.806 & 1.23 \\
PMPC $_{113}$ & 3.23 & 113 & 3.36 & 1.93 & 1.17 \\
PMPC $_{362}$ & 12.0 & 362 & 10.7 & 4.53 & 1.97
\end{tabular}

Abbreviations: DP, number-average degree of polymerization; $M_{\mathrm{n}}(\mathrm{GPC})$, number-average molecular weight estimated from gel-permeation chromatography; $M_{n}$ (NMR), number-average molecular weight estimated from ${ }^{1} \mathrm{H}$ NMR; $M_{n}$ (theoretical), number-average molecular weight estimated from Equation (2); $M_{\mathrm{w}} / M_{\mathrm{n}}$, molecular weight distribution; PMPC, poly(2(methacryloyloxy)ethyl phosphorylcholine). protons. The value of $M_{\mathrm{n}}$ (NMR) for $\mathrm{PMPC}_{n}$ can be calculated from the corresponding DP, which is close to $M_{\mathrm{n}}$ (theoretical). The GPC peak for $\mathrm{PMPC}_{113}$ was unimodal (Supplementary Figure S2). The $M_{\mathrm{w}} / M_{\mathrm{n}}$ value for $\mathrm{PMPC}_{113}$ was 1.17 , suggesting that $\mathrm{PMPC}_{113}$ had a well-controlled structure. The $M_{\mathrm{n}}(\mathrm{GPC})$ value was an estimated value because poly(sodium $p$-styrenesulfonate) was used as a standard for the calibration.

Preparation and characterization of fullerene/ $\mathrm{PMPC}_{n}$ complexes The sample preparation method is important for the solubilization of fullerenes in water using $\mathrm{PMPC}_{n}$. Fullerene and $\mathrm{PMPC}_{n}$ powders were ground with a mortar and pestle for $30 \mathrm{~min}$ to achieve homogeneity. ${ }^{29}$ The relationship between the amount of fullerene solubilized in water using $\mathrm{PMPC}_{n}$ and the duration of grinding was determined. The amount of fullerene solubilized was not increased by grinding for $>30 \mathrm{~min}$. Therefore, the grinding time was kept constant at $30 \mathrm{~min}$ to prepare the fullerene/PMPC $n$ complexes. Insoluble matter was removed by centrifugation. All sample solutions were filtered with a $0.45-\mu \mathrm{m}$ membrane filter.

To measure UV-vis absorption spectra for $\mathrm{C}_{60} / \mathrm{PMPC}_{113}$ and $\mathrm{C}_{70} / \mathrm{PMPC}_{113}$ complexes in water with varying fullerene concentrations, the sample solutions were diluted with water because the absorbance from the original aqueous complex solutions was too high to measure using a UV-vis absorption spectrometer (Figure 2). The original absorbance was calculated from the absorption spectra and the dilution ratio. The $\mathrm{C}_{60} / \mathrm{PMPC}_{113}$ complex indicated $\mathrm{C}_{60}$ absorption peaks at 215,265 and $340 \mathrm{~nm}$, which increased until $\left[\mathrm{C}_{60}\right] \leqslant 1.1 \mathrm{~g} \mathrm{l}^{-1}$ while increasing the $\mathrm{C}_{60}$ feed concentration. The $\mathrm{C}_{70}$ absorption peaks at 215, 240 and $384 \mathrm{~nm}$ for the $\mathrm{C}_{70} / \mathrm{PMPC}_{113}$ complex increased until $\left[C_{70}\right] \leqslant 0.5 \mathrm{gl}^{-1}$ while increasing the $C_{70}$ feed concentration.
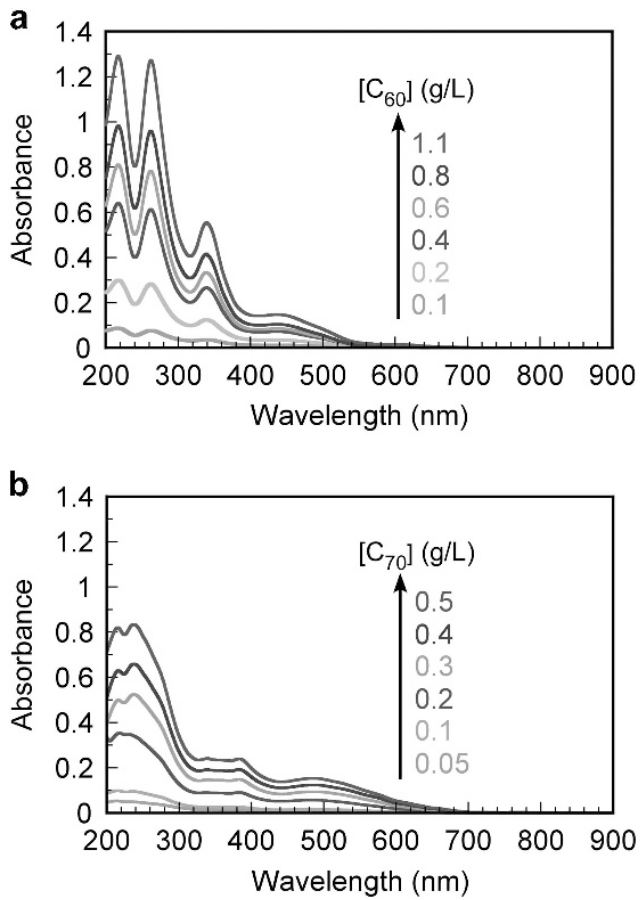

Figure 2 UV-vis adsorption spectra for (a) $\mathrm{C}_{60} / \mathrm{PMPC}_{113}$ and (b) $\mathrm{C}_{70} / \mathrm{PMPC}_{113}$ complexes at various fullerene concentrations in water. The original solutions were diluted to $1 / 100$ because the absorbance was too high. PMPC, poly(2-(methacryloyloxy)ethyl phosphorylcholine); UV-vis, ultraviolet-visible. A full color version of this figure is available at the Polymer Journal online. 
These absorption peaks were similar to those for $\mathrm{C}_{60}$ and $\mathrm{C}_{70}$ in organic solvents. ${ }^{16}$ These observations indicate that $\mathrm{PMPC}_{n}$ can solubilize $\mathrm{C}_{60}$ and $\mathrm{C}_{70}$ in water.

The relationship between the feed amount of fullerene and the amount of fullerene dissolved in water using $\mathrm{PMPC}_{113}$ is shown in Figure 3. The solubilized amounts were calculated from the absorbance and extinction coefficients for $\mathrm{C}_{60}\left(68.0 \mathrm{Lg}^{-1} \mathrm{~cm}^{-1}\right.$ at $\left.340 \mathrm{~nm}\right)$ and $\mathrm{C}_{70}\left(40.4 \mathrm{Lg}^{-1} \mathrm{~cm}^{-1}\right.$ at $\left.384 \mathrm{~nm}\right){ }^{18}$ The maximum concentrations of $\mathrm{C}_{60}$ and $\mathrm{C}_{70}$ in water using $\mathrm{PMPC}_{113}$ at $C_{\mathrm{p}}=1 \mathrm{~g} \mathrm{l}^{-1}$ were 0.67 and $0.49 \mathrm{gl}^{-1}$, respectively. The solubilized amounts of fullerenes using $\mathrm{PMPC}_{113}$ were higher than those in previous reports. The reported concentration of $\mathrm{C}_{60}$ in water using surfactants, such as lecithin, was $0.012 \mathrm{~g} \mathrm{l}^{-1} .{ }^{16}$ Yamakoshi et al. ${ }^{18}$ reported that solubilized $\mathrm{C}_{60}$ and $\mathrm{C}_{70}$ concentrations using PVP in water were 0.4 and $0.2 \mathrm{~g} \mathrm{l}^{-1}$, respectively.

Although the pendant phosphorylcholine groups in $\mathrm{PMPC}_{n}$ are hydrophilic, the main chain of methacrylate is slightly more hydrophobic than the pendant group. The methacrylate main chain in $\mathrm{PMPC}_{n}$ may interact with hydrophobic fullerene. To confirm hydrophobic interactions between the main chain and fullerene, solubilization tests for $\mathrm{C}_{60}$ in water were performed using commercially available PMA $\left(M_{\mathrm{w}}=9.50 \times 10^{3}\right)$ and PAA $\left(M_{\mathrm{W}}=2.50 \times 10^{4}\right)$ powders. PMA at $C_{\mathrm{p}}=1 \mathrm{gl}^{-1}$ dissolved $\mathrm{C}_{60}$ in water with $\left[\mathrm{C}_{60}\right]=0.37 \mathrm{~g} \mathrm{l}^{-1}$. In contrast, PAA could not dissolve $\mathrm{C}_{60}$ in water. These results suggest that a methacrylate-type main chain structure may be extremely important for the formation of a fullerene/PMPC complex. The amount of fullerene solubilized by PMA was less than that by $\mathrm{PMPC}_{n}$. Thus the solubilization of fullerenes may require hydrophobic interactions between the methacrylate polymer

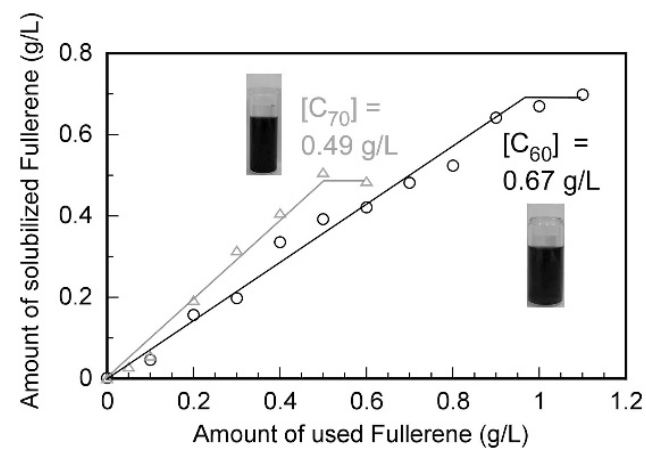

Figure 3 Plots of solubilized amounts of $C_{60}(0)$ and $C_{70}(\triangle)$ as a function of feed concentration of $\mathrm{C}_{60}$ or $\mathrm{C}_{70}$. A full color version of this figure is available at Polymer Journal online.

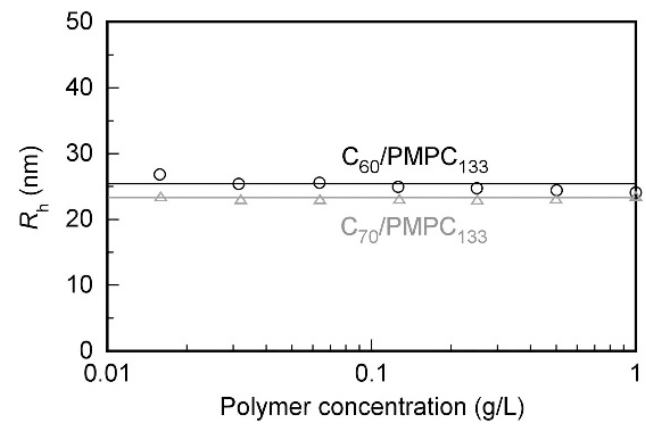

Figure $4 R_{\mathrm{h}}$ of $\mathrm{C}_{60} / \mathrm{PMPC}_{113}(\circ)$ and $\mathrm{C}_{70} / \mathrm{PMPC}_{113}$ complexes $(\triangle)$ as a function of $C_{\mathrm{p}}$. $C_{\mathrm{p}}$, polymer concentration; PMPC, poly(2-(methacryloyloxy) ethyl phosphorylcholine); $R_{\mathrm{h}}$, hydrodynamic radius. A full color version of this figure is available at the Polymer Journal online. backbone and fullerene as well as interactions between the pendant phosphorylcholine groups in $\mathrm{PMPC}_{n}$ and fullerene. To confirm the influence of the $M_{\mathrm{w}}$ of $\mathrm{PMPC}_{n}$, solubilization of $\mathrm{C}_{60}$ in water was performed using $\mathrm{PMPC}_{n}$ with a low $\left(M_{\mathrm{n}}(\mathrm{NMR})=1.89 \times 10^{4}\right)$ and a high $\left(M_{\mathrm{n}}(\mathrm{NMR})=1.07 \times 10^{5}\right) M_{\mathrm{w}}$. The maximum concentrations of $\mathrm{C}_{60}$ in water using $\mathrm{PMPC}_{64}$ and $\mathrm{PMPC}_{362}$ at $C_{\mathrm{p}}=1 \mathrm{~g} \mathrm{l}^{-1}$ were 0.76 and $0.44 \mathrm{gl}^{-1}$, respectively. The maximum $\mathrm{C}_{60}$ concentrations in water increased as the $M_{\mathrm{w}}$ of $\mathrm{PMPC}_{n}$ decreased. For every polymer chain, the number of solubilized $\mathrm{C}_{60}$ molecules can be calculated from the molar concentrations of polymer and solubilized $\mathrm{C}_{60}$. The number of $\mathrm{C}_{60}$ molecules that could be solubilized by a single polymer chain of $\mathrm{PMPC}_{64}, \mathrm{PMPC}_{113}, \mathrm{PMPC}_{362}$ and PMA was $20,31,65$ and 7 , respectively.

The stability of the complex during dilution with water was studied. The hydrodynamic radius $\left(R_{\mathrm{h}}\right)$ values for the complexes were plotted as a function of $C_{\mathrm{p}}$ (Figure 4). The $R_{\mathrm{h}}$ values for the complexes were kept constant and were independent of $C_{\mathrm{p}}$ in the region of $1-0.05 \mathrm{gl}^{-1}$. The complexes were stable even at $0.05 \mathrm{gl}^{-1}$ upon dilution of $C_{\mathrm{p}}$. When $C_{\mathrm{p}}$ was diluted to a concentration $<0.05 \mathrm{~g} \mathrm{l}^{-1}$, DLS data could not be obtained owing to low scattering intensity.

To characterize the complexes in more detail, SLS measurements were performed for $\mathrm{C}_{60} / \mathrm{PMPC}_{113}$ and $\mathrm{C}_{70} / \mathrm{PMPC}_{113}$ complexes in water (Supplementary Figure S3). The results from light scattering measurements are summarized in Table 2. The values of $M_{\mathrm{w}}$ and $R_{\mathrm{g}}$ for the $\mathrm{C}_{60} / \mathrm{PMPC}_{113}$ complex were larger than were those for $\mathrm{C}_{70} / \mathrm{PMPC}_{113}$. The $A_{2}$ values for $\mathrm{C}_{60} / \mathrm{PMPC}_{113}$ and $\mathrm{C}_{70} / \mathrm{PMPC}_{113}$ were $1.19 \times 10^{-3}$ and $2.77 \times 10^{-3} \mathrm{~cm}^{3} \cdot \mathrm{mol} \mathrm{g}^{-2}$, respectively. The complex using $\mathrm{C}_{60}$ had a small $A_{2}$, which indicates that the solubility of $\mathrm{C}_{60} / \mathrm{PMPC}_{113}$ in water was lower than that of $\mathrm{C}_{70} / \mathrm{PMPC}_{113} .{ }^{30,31}$ The $R_{\mathrm{g}} / R_{\mathrm{h}}$ value is related to the shape and polydispersity of aggregates in solution. The theoretical $R_{\mathrm{g}} / R_{\mathrm{h}}$ values for rigid hard spheres and spherical aggregates are 0.78 and 1.0 , respectively. ${ }^{32-35}$ The $R_{\mathrm{g}} / R_{\mathrm{h}}$ values for random coil and ellipsoidal aggregates are 1.3-1.5. Thread-like and low-density aggregates with a high polydispersity index indicate larger $R_{\mathrm{g}} / R_{\mathrm{h}}$ values. The shapes of the fullerene/ $\mathrm{PMPC}_{113}$ complexes may be spherical because the $R_{\mathrm{g}} / R_{\mathrm{h}}$ values for the complexes were close to 1 . The densities of $\mathrm{C}_{60} / \mathrm{PMPC}_{113}$ and $\mathrm{C}_{70} / \mathrm{PMPC}_{113}$ complexes calculated from the apparent $M_{\mathrm{w}}$ and $R_{\mathrm{g}}$ values estimated from SLS were 0.103 and $0.064 \mathrm{~g} \mathrm{~cm}^{-3}$, respectively. The maximum number of fullerenes for every $\mathrm{PMPC}_{113}$ chain was calculated from the molar ratio of $\mathrm{PMPC}_{113}$ and fullerene in water using UV-vis absorption data. The number of $\mathrm{C}_{60}$ and $\mathrm{C}_{70}$ in one $\mathrm{PMPC}_{113}$ polymer chain was 31 and 20 , respectively. The aggregation number $\left(N_{\mathrm{agg}}\right)$ for the complex was calculated from the apparent $M_{\mathrm{w}}$ for the complex and the $M_{\mathrm{w}}$ of a single polymer chain with the accompanying fullerenes. The $N_{\text {agg }}$ was defined as the total number of $\mathrm{PMPC}_{113}$ chains in one complex. The $N_{\text {agg }}$ values for $\mathrm{C}_{60} / \mathrm{PMPC}_{113}$

Table 2 Dynamic and static light scattering data for fullerene/ PMPC113 complexes in water at $25^{\circ} \mathrm{C}$

\begin{tabular}{lcccccc}
\hline Samples & $\mathrm{R}_{h}(n m)$ & $\mathrm{M}_{w}(S L S) \times 10^{-6}$ & $\mathrm{R}_{g}(\mathrm{~nm})$ & $\mathrm{A}_{2} \times 10^{3}(\mathrm{~mol}$ \\
$\left.\mathrm{m} / g^{-2}\right)$ & $\mathrm{R}_{g} \mathrm{R}_{h}$ & $\mathrm{~N}_{a g g}$ \\
\hline $\mathrm{C}_{60} / \mathrm{PMPC}_{113}$ & 25.1 & 5.37 & 27.6 & 1.19 & 1.10 & 96 \\
$\mathrm{C}_{70} / \mathrm{PMPC}_{113}$ & 23.2 & 1.99 & 23.2 & 2.77 & 1.00 & 40 \\
\hline
\end{tabular}

Abbreviations: $A_{2}$, the second virial coefficient; $M_{\mathrm{w}}(\mathrm{SLS})$, weight-average molecular weight estimated with static light scattering; $N_{\text {agg }}$, aggregation number of the fullerene/PMPC 113 complex; PMPC, poly(2-(methacryloyloxy)ethyl phosphorylcholine); $R_{\mathrm{g}}, z$-average radius of gyration; $R_{\mathrm{h}}$, hydrodynamic radius.

$N_{\text {agg }}$ values are calculated from the $M_{\mathrm{w}}$ of the complex determined by SLS and the $M_{\mathrm{w}}$ of the corresponding single $\mathrm{PMPC}_{n}$ chain. 

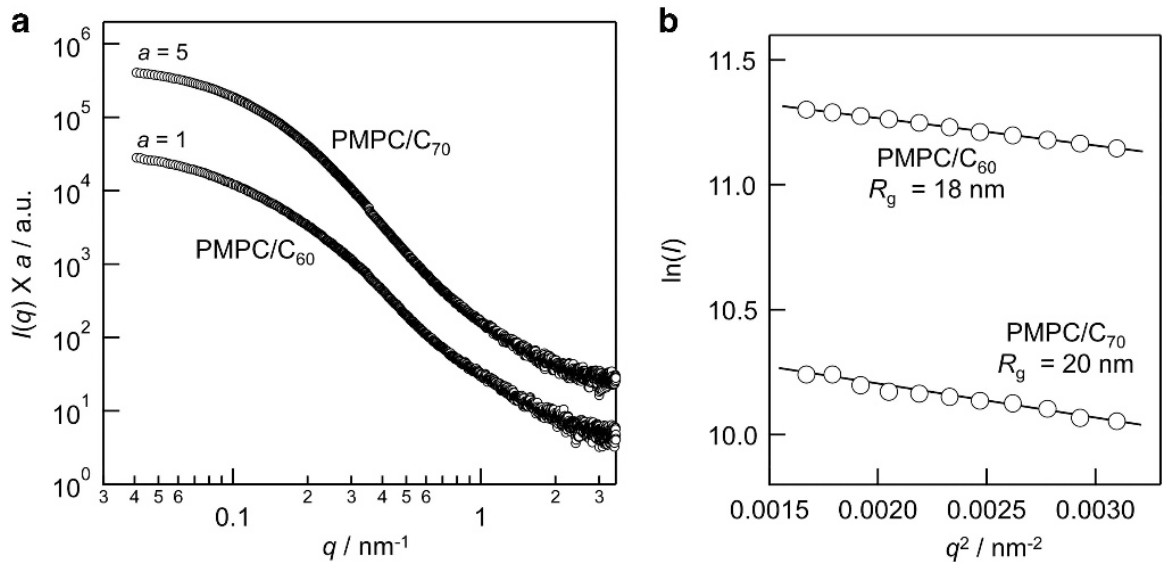

Figure 5 (a) SAXS profiles and (b) Guinier plots for $\mathrm{C}_{60} / \mathrm{PMPC}_{113}$ and $\mathrm{C}_{70} / \mathrm{PMPC}_{113}$ complexes in water. a: shift factor, $q$ : the magnitude of the scattering vector and $/(q)$ : scattering intensity.
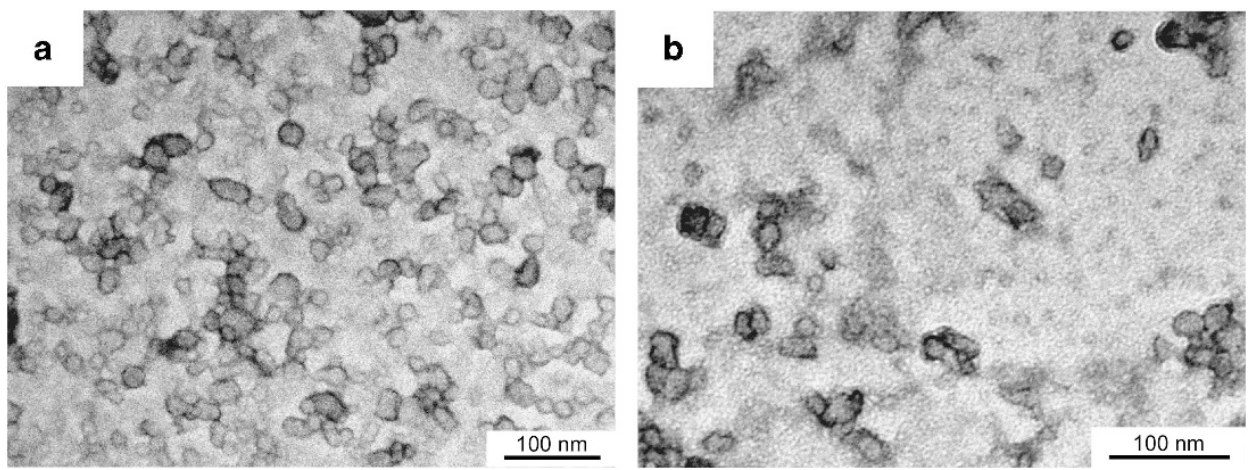

Figure 6 TEM images for (a) $\mathrm{C}_{60} / \mathrm{PMPC}_{113}$ and (b) $\mathrm{C}_{70} / \mathrm{PMPC}_{113}$ complexes. PMPC, poly(2-(methacryloyloxy)ethyl phosphorylcholine); TEM, transmission electron microscopy.<smiles>O=C(O)CCc1c2ccccc2c(CC(=O)O)c2ccccc12</smiles>

ADPA

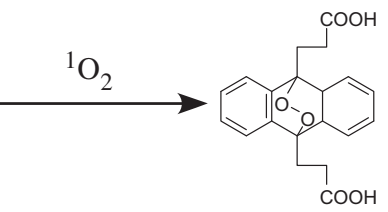

ADPA endoperoxide
Scheme 1 Photooxidation of ADPA by singlet oxygen. ADPA, 9, 10-anthracendipropionic acid.

and $\mathrm{C}_{70} / \mathrm{PMPC}_{113}$ complexes were 96 and 40, respectively. The number of $\mathrm{C}_{60}$ and $\mathrm{C}_{70}$ fullerenes included in one complex was 2995 and 784, respectively.

To confirm the structure of the complex, we performed SAXS measurements (Figure 5). The $R_{\mathrm{g}}$ values for $\mathrm{PMPC} / \mathrm{C}_{60}$ and PMPC/C 70 were 18 and $20 \mathrm{~nm}$, respectively, as obtained from Guinier plots. These values are smaller than those obtained from SLS measurements. As X-rays scatter owing to nanoscale electron density inhomogeneities within samples, they effectively highlight the clustered fullerene parts in the complex. ${ }^{36}$ The $R_{\mathrm{g}}$ of $\mathrm{C}_{70} / \mathrm{PMPC}$ was larger than that of $\mathrm{C}_{60} / \mathrm{PMPC}$, as estimated from SAXS measurements. This observation suggests that the aggregate formed from $\mathrm{C}_{70}$ in the complex was swollen owing to incorporation of PMPC chains and water into the aggregate.

TEM measurements were performed to confirm the size and shape of the fullerene/PMPC ${ }_{113}$ complex (Figure 6). The $\mathrm{C}_{60} / \mathrm{PMPC}_{113}$ and
$\mathrm{C}_{70} / \mathrm{PMPC}_{113}$ complexes had a distorted spherical shape. The average diameters estimated from TEM images for $\mathrm{C}_{60} / \mathrm{PMPC}_{113}$ and $\mathrm{C}_{70} / \mathrm{PMPC}_{113}$ complexes were 29 and $24 \mathrm{~nm}$, respectively. The sizes estimated from TEM were slightly smaller than were those estimated from light scattering measurements because the complexes may shrink during the drying process while preparing TEM samples.

\section{Generation of singlet oxygen}

Fullerenes can be excited by light, and the energy is subsequently transferred to ground-state oxygen to efficiently generate singlet oxygen. The photooxidation of ADPA by singlet oxygen can be applied for the detection of generated singlet oxygen atoms using a photosensitizer (Scheme 1). ${ }^{25}$ To confirm the generation of singlet oxygen atoms from fullerene/PMPC ${ }_{n}$ complexes upon visible light irradiation, ADPA was used to detect the singlet oxygen atoms in water. Photooxidation of ADPA to generate ADPA endoperoxide by singlet oxygen is indicated by observing a decrease in the UV-vis absorption peaks of ADPA. Changes in the UV-vis absorption spectra of ADPA were measured in the presence of fullerene/PMPC ${ }_{n}$ complexes in water upon visible light irradiation at $\geqslant 420 \mathrm{~nm}$, as shown in Figure 7. The polymer concentration was diluted to $0.021 \mathrm{gl}^{-1}$ in water because the absorbance of fullerenes was too high for the original solutions at $C_{\mathrm{p}}=1 \mathrm{~g} \mathrm{l}^{-1}$. The concentrations of $\mathrm{C}_{60}$ and $\mathrm{C}_{70}$ were 0.0141 and $0.0103 \mathrm{~g} \mathrm{l}^{-1}$, respectively. The concentrations of ADPA used in the $\mathrm{C}_{60}$ and $\mathrm{C}_{70}$ experiments were 0.0377 and $0.0439 \mathrm{gl}^{-1}$, respectively. The UV-vis spectra were calibrated by 

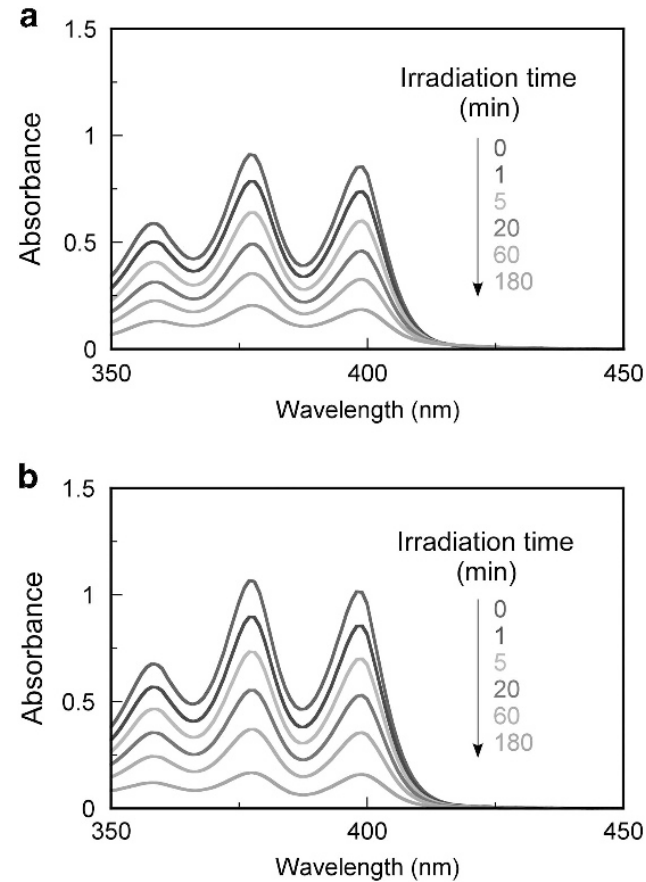

Figure 7 Changes in UV-vis absorption spectra of ADPA in the presence of (a) $\mathrm{C}_{60} / \mathrm{PMPC}_{113}$ and (b) $\mathrm{C}_{70} / \mathrm{PMPC}_{113}$ complexes in water upon visible light irradiation $(\geqslant 420 \mathrm{~nm})$. Fullerene absorptions were subtracted from the original spectra for calibration. Irradiation times are indicated in the figure. ADPA, 9,10-anthracendipropionic acid, PMPC, poly(2-(methacryloyloxy)ethyl phosphorylcholine); UV-vis, ultraviolet-visible. A full color version of this figure is available at the Polymer Journal online.

subtracting the fullerene absorption. The absorbance of ADPA in the presence of the complex decreased with increasing irradiation time. After $180 \mathrm{~min}$ of irradiation, the absorbance values at $399 \mathrm{~nm}$ of ADPA in the presence of $\mathrm{C}_{60} / \mathrm{PMPC}_{113}$ and $\mathrm{C}_{70} / \mathrm{PMPC}_{113}$ complexes were 0.186 and 0.160 , respectively. This observation indicates that $\mathrm{C}_{70} / \mathrm{PMPC}_{113}$ can oxidize ADPA more efficiently than $\mathrm{C}_{60} / \mathrm{PMPC}_{113}$. The amounts of singlet oxygen generated from $\mathrm{C}_{70} / \mathrm{PMPC}_{113}$ were higher than those from $\mathrm{C}_{60} / \mathrm{PMPC}_{113}$ by light irradiation above $420 \mathrm{~nm}$, presumably because the absorption wavelength of $\mathrm{C}_{70} / \mathrm{PMPC}_{113}$ was longer than that of $\mathrm{C}_{60} / \mathrm{PMPC}_{113}$.

\section{CONCLUSIONS}

Hydrophilic and biocompatible $\mathrm{PMPC}_{n}$ with a well-controlled structure was prepared via RAFT-controlled radical polymerization. Fullerene/PMPC $n$ complexes were prepared by mixing fullerene and $\mathrm{PMPC}_{n}$ powders. Fullerenes could be solubilized in water using $\mathrm{PMPC}_{n}$ with a higher concentration than those reported previously. Hydrophobic interactions of the main chain with fullerene and interactions between the pendant phosphorylcholine and fullerene may be important for fullerene solubilization. The $R_{\mathrm{h}}$ values for $\mathrm{C}_{60} / \mathrm{PMPC}_{113}$ and $\mathrm{C}_{70} / \mathrm{PMPC}_{113}$ complexes were 25.1 and $23.2 \mathrm{~nm}$, respectively. The number of $\mathrm{C}_{60}$ and $\mathrm{C}_{70}$ fullerenes in one complex was 2995 and 784, respectively. Singlet oxygen was generated from fullerene $/ \mathrm{PMPC}_{n}$ complexes upon visible light irradiation $>420 \mathrm{~nm}$. These fullerene/ $\mathrm{PMPC}_{n}$ complexes are promising candidates for application in PDT.

\section{CONFLICT OF INTEREST}

The authors declare no conflict of interest.

\section{ACKNOWLEDGEMENTS}

This work was financially supported by a Grant-in-Aid for Scientific Research (No. 25288101) from the Japan Society for the Promotion of Science (JSPS) and the Cooperative Research Program 'Network Joint Research Center for Materials and Devices' (No. 2015467). All SAXS measurements were performed at the SPring-8 beamline (2016A1242, 2016A1619).

1 Jensen, A. W., Wilson, S. R. \& Schuster, D. I. Biological applications of fullerenes. Biological applications of fullerenes. Bioorg. Med. Chem. 4, 767-779 (1996).

2 Nakamura, E. \& Isobe, H. Functionalized fullerenes in water. The first 10 years of their chemistry, biology, and nanoscience. Acc. Chem. Res. 36, 807-815 (2003).

3 Chinazi, R. F., Sijbesma, R., Srdanov, G., Hill, C. L. \& Wudl, F. Synthesis and virucidal activity of a water-soluble, configurationally stable, derivatized $\mathrm{C}_{60}$ fullerene. Antimicrob. Agents Chemother. 37, 1707-1710 (1993).

4 Sera, N., Tokiwa, H. \& Miyata, N. Mutagenicity of the fullerene $\mathrm{C}_{60}$-generated singlet oxygen dependent formation of lipid peroxides. Carcinogenesis 17, 2163-2169 (1996).

5 Chiang, L. Y., Lu, F. J. \& Lin, J. T. Free radical scavenging activity of water-soluble fullerenols. J. Chem. Soc., Chem. Commun. 1283-1284 (1995).

6 Tabata, Y. \& Ikeda, Y. Biological functions of fullerene. Pure Appl. Chem. 71, 2047-2053 (1999).

7 Yusa, S., Awa, S., Ito, M., Kawase, T., Takada, T., Nakashima, K., Liu, D., Yamago, S. \& Morishima, Y. Solubilization of $\mathrm{C}_{60}$ by micellization with a thermoresponsive block copolymer in water: Characterization, singlet oxygen generation, and DNA photocleavage. J. Polym. Sci. A Polym. Chem. 49, 2761-2770 (2011).

8 Torres, V. M., Posa, M., Srdjenovic, B. \& Simplício, A. L. Solubilization of fullerene $C_{60}$ in micellar solutions of different solubilizers. Colloid Surf. B Biointerfaces $\mathbf{8 2}$, 46-53 (2011).

9 Chiang, L. Y., Wang, L. Y., Swirczewski, J. W., Soled, S. \& Cameron, S. Efficient synthesis of polyhydroxylated fullerene derivatives via hydrolysis of polycyclosulfated Precursors. J. Org. Chem. 59, 3960-3968 (1994).

10 Scrivens, W. A., Tour, J. M., Creek, K. E. \& Pirisi, L. Synthesis of ${ }^{14} \mathrm{C}$-labeled $\mathrm{C}_{60}$, its suspension in water, and its uptake by human keratinocytes. J. Am. Chem. Soc. 116, 4517-4518 (1994).

11 Deguchi, S., Mukai, S., Tsudome, M. \& Horikoshi, K. Facile generation of fullerene nanoparticles by hand-grinding. Adv. Mater. 18, 729-732 (2006).

12 Andersson, T., Nilsson, K., Sundahl, M., Westman, G. \& Wennerstrom, O. C 60 embedded in $\gamma$-cyclodextrin: a water-soluble fullerene. J. Chem. Soc. Chem. Commun. 8, 604-606 (1992).

13 Komatsu, K., Fujiwara, K., Murata, Y. \& Braun, T. Aqueous solubilization of crystalline fullerenes by supramolecular complexation with $\gamma$-cyclodextrin and sulfocalix[8]arene under mechanochemical high-speed vibration milling. J. Chem. Soc. Perkin Trans. 1, 2963-2966 (1999).

14 Wang, H. M. \& Wenz, G. Molecular solubilization of fullerene $C_{60}$ in water by $\gamma$-cyclodextrin thioethers. Beilstein J. Org. Chem. 8, 1644-1651 (2012).

15 Atwood, J. L., Koutsantonis, G. A. \& Raston, C. L. Purification of $\mathrm{C}_{60}$ and $\mathrm{C}_{70}$ by selective complexation with calixarenes. Nature 368, 229-231 (1994).

16 Hungerbühler, H., Guldi, D. M. \& Asmus, K. D. Incorporation of $\mathrm{C}_{60}$ into artificial lipid membranes. J. Am. Chem. Soc. 115, 3386-3387 (1993).

17 Ikeda, A., Sato, T., Kitamura, K., Nishiguchi, K., Sasaki, Y., Kikuchi, J., Ogawa, T., Yogo., K. \& Takeya, T. Efficient photocleavage of DNA utilising water-soluble lipid membrane-incorporated [60]fullerenes prepared using a [60]fullerene exchange method. Org. Biomol. Chem. 3, 2907-2909 (2005).

18 Yamakoshi, Y. N., Yagami, T., Fukuhara, K., Sueyoshi, S. \& Miyata, N. Solubilization of fullerenes into water with polyvinylpyrrolidone applicable to biological tests. Chem. Commun. 4, 517-518 (1994).

19 Tsuchiya, T., Yamakoshi, Y. \& Miyata, N. A novel promoting action of fullerene $C_{60}$ on the chondrogenesis in rat embryonic limb bud cell culture system. Biochem. Biophys. Res. Commun. 206, 885-894 (1995).

20 Matsumura, Y. \& Maeda, H. A new concept for macromolecular therapeutics in cancer chemotherapy: mechanism of tumoritropic accumulation of proteins and the antitumor agent smancs. Cancer Res. 46, 6387-6392 (1986).

21 Ishihara, K., Ueda, T. \& Nakabayashi, N. Preparation of phospholipid polymers and their properties as polymer hydrogel membranes. Polym. J. 22, 355-360 (1990).

22 Ohno, S., Hasegawa, S., Liu, H., Ishihara, K. \& Yusa, S. Aggregation behavior in water of amphiphilic diblock copolymers bearing biocompatible phosphorylcholine and cholesteryl groups. Polym. J. 47, 71-76 (2015).

23 Iwasaki, Y., Ijuin, M., Mikami, A., Nakabayashi, N. \& Ishihara, K. Behavior of blood cells in contact with water-soluble phospholipid polymer. J. Biomed. Mater. Res. 46, 360-367 (1999).

24 Mitsukami, Y., Donovan, M. S., Lowe, A. B. \& McCormick, C. L. Water-soluble polymers. 81. Direct synthesis of hydrophilic styrenic-based homopolymers and block copolymers in aqueous solution via RAFT. Macromolecules 34, 2248-2256 (2001).

25 Lindig, B. A., Rodgers, M. A. J. \& Schaap, A. P. Determination of the lifetime of singlet oxygen in $\mathrm{D}_{2} \mathrm{O}$ using 9,10 -anthracenedipropionic acid, a water-soluble probe. J. Am. Chem. Soc. 102, 5590-5593 (1980).

26 Yokoyma, Y. \& Yusa., S. Water-soluble complexes formed from hydrogen bonding interactions between a poly(ethylene glycol)-containing triblock copolymer and poly (methacrylic acid). Polym. J. 45, 985-992 (2013). 
27 Naruse, K., Eguchi, K., Akiba, I., Sakurai, K., Masunaga, H., Ogawa, H. \& Fossey, J. S. Flexibility and cross-sectional structure of an anionic dual-surfactant wormlike micelle explored with small-angle X-ray scattering coupled with contrast variation technique. J. Phys. Chem. B 113, 10222-10229 (2009).

28 Akiba, I., Terada, N., Hashida, S., Sakurai, K., Sato, T., Shiraishi, K., Yokoyama, M., Masunaga, H., Ogawa, H., Ito, K. \& Yagi, N. Encapsulation of a hydrophobic drug into a polymer-micelle core explored with synchrotron SAXS. Langmuir 26, 7544-7551 (2010).

29 Yusa, S., Morihara, M., Nakai, K., Fujii, S., Nakamura, Y., Maruyama, A. \& Shimada, N. Thermo-responsive liquid marbles. Polym. J. 46, 145-148 (2014).

30 Yusa, S., Fukuda, K., Yamamoto, T., Ishihara, K. \& Morishima, Y. Synthesis of well-defined amphiphilic block copolymers having phospholipid polymer sequences as a novel biocompatible polymer micelle reagent. Biomacromolecules 6, 663-670 (2005).

31 Quintana, J. R., Jánez, M. D., Villacampa, M. \& Katime, I. Diblock copolymer micelles in solvent binary mixtures. 1. Selective solvent/precipitant. Macromolecules 28, 4139-4143 (1995).
32 Villacampa, M., Apodaca, E. D., Quintana, J. R. \& Katime, I. Diblock copolymer micelles in solvent binary mixtures. 2. Selective solvent/good solvent. Macromolecules 28, 4144-4149 (1995).

33 Huber, K., Bantle, S., Lutz, P. \& Burchard, W. Hydrodynamic and thermodynamic behavior of short-chain polystyrene in toluene and cyclohexane at $34.5^{\circ} \mathrm{C}$. Macromolecules 18, 1461-1467 (1985).

34 Akcasu, A. Z. \& Han, C. C. Molecular weight and temperature dependence of polymer dimensions in solution. Macromolecules 12, 276-280 (1979).

35 Konishi, T., Yoshizaki, T. \& Yamakawa, H. On the "Universal Constants" $\rho$ and $\Phi$ of flexible polymers. Macromolecules 24, 5614-5622 (1991).

36 Hollamby, M. J., Karny, M., Bomans, P. H. H., Sommerdijk, N. A. J. M., Saeki, A., Seki, S., Minamikawa, H., Grillo, I., Pauw, B. R., Brown, P., Eastoe, J., Möhwald, H. \& Nakanishi, T. Directed assembly of optoelectronically active alkyl- $\pi$-conjugated molecules by adding $n$-alkanes or $\pi$-conjugated species. Nat. Chem. 6, 690-696 (2014).

Supplementary Information accompanies the paper on Polymer Journal website (http://www.nature.com/pj) 